\title{
Assessing Attention: Comparison of Response-Inhibition and Traditional Continuous Performance Tests*
}

\author{
Joan C. Ballard \\ State University of New York, College at Geneseo, NY, USA
}

\begin{abstract}
The purpose of this study was to compare a recently developed response-inhibition task (Conners, 1995) to slow- and fast-event-rate versions of the traditional A-X Continuous Performance Test (CPT). Among 146 normal adults, results revealed significant differences between tasks in omission and commission error rates, reaction time, reaction time variability, and responses to critical signals. Effects of environmental noise and participant anxiety also differed for the three tasks. Traditional CPTs produced time-related performance decrements, but the response-inhibition task produced improvement across initial blocks of trials. The response-inhibition task may measure "executive control" rather than sustained attention, and therefore may represent functions of different brain systems.
\end{abstract}

In both clinical practice and experimental research, neuropsychologists need tests of fundamental attention skills, including the ability to sustain attention over time. The continuous performance test (CPT) is a "vigilance task" used to study sustained attention and to assess "attention deficits". Several variations of the task have been marketed, some of which differ markedly from the traditional CPT. For such tests to be useful, the factors affecting performance must be carefully delineated and compared with the rich body of literature on vigilance tasks. The purpose of the present study was to compare one of the newer tasks with traditional CPTs. The following sections present a description of the traditional CPT, a brief overview of factors affecting CPT performance, and a summary of neuroanatomical models of attention. Next, the characteristics of the
"Standard" task marketed by Multi-Health Systems (MHS-Standard; Conners, 1995) are compared to those of traditional CPTs. Finally, results are presented from an empirical study of performance on the MHS-Standard and two variations of the traditional CPT.

\section{The Traditional Continuous Performance Test (CPT)}

The traditional CPT involves watching a computer screen for specified symbols in a sequence of symbols. When this "critical signal" is detected, the participant is typically required to respond by pressing a computer key. Failure to press the key when the critical signal appears is an "omission error". Pressing the key at any other time is a "commission error". Reaction time is the latency between critical signal onset and the participant's

\footnotetext{
* The author would like to acknowledge the assistance of the following students during data collection and initial analysis: Karin J. Wallace, Joseph R. Smith, Kelly J. Bloomfield, Eun J. Lim, Carrie W. Bailey, Michael D. Wanderer, Kellee Garney, and Sarah Dodson. Portions of these data were presented at the 106th Annual Convention of the American Psychological Association, August 14-18, 1998, San Francisco, California.

Address correspondence to: Joan C. Ballard, Ph.D., Department of Psychology, SUNY Geneseo, Geneseo, NY 14454, USA. Tel.: (716) 245-5539. E-mail: ballard@ geneseo.edu Accepted for publication: June 22, 2000.
} 
response. Rosvold, Mirsky, Sarason, Bransome, and Beck (1956) devised the first version of the CPT, which required participants to press a key when the letter " $\mathrm{X}$ " appeared, or when " $\mathrm{X}$ " appeared immediately after "A". These authors demonstrated that the task could discriminate neurological patients from other patients.

\section{Factors Affecting CPT Performance}

Performance on CPT and other vigilance tasks depends on direct and interactive effects of three categories of factors: (1) task parameters; (2) participant characteristics; and (3) environmental conditions (see reviews by Ballard, 1996a; Berch \& Kanter, 1984; Davies, Jones, \& Taylor, 1984; Hancock, 1984; Hockey, 1984; Koelega \& Brinkman, 1986; Loeb, 1986; Loeb \& Alluisi, 1984; McGrath, Harabedian, \& Buckner, 1968; Parasuraman \& Haxby, 1993; Smith, 1989; Tarver \& Hallahan, 1974; Warm \& Jerison, 1984). The first category of factors includes characteristics of the task itself. In general, performance is impaired by longer task durations, infrequent critical signals, low signal-to-nonsignal ratios, multiple sources of information, or low intensity, brief, or degraded stimuli (Baker, 1959, Davies \& Hockey, 1966; Knopf \& Mabel, 1975; Mackworth, 1950; Parasuraman \& Mouloua, 1987). The most potent of task parameters is speed of stimulus presentation, which is usually confounded with inter-stimulus interval (ISI) and/or stimulus duration. In general, tasks with faster event rates produce more errors, slower reaction times, and steeper performance decrements (Ballard, 1996b; Broadbent \& Gregory, 1965; Parasuraman, 1979; Parasuraman \& Giambra, 1991).

The second category of factors related to vigilance performance includes a variety of individual characteristics, such as age (Giambra \& Quilter, 1988; Levy, 1980; Seidel \& Joschko, 1991), sleep deprivation (see Krueger, 1989), use of CNS depressants or stimulants (Coons, Klorman, \& Borgstedt, 1987; Golombok, Moodley, \& Lader, 1988; Linnoila, Erwin, Cleveland, Logue, \& Gentry, 1978; Rapport, Carlson, Kelly, \& Pataki, 1993; Rohrbaugh, et al., 1988; Smith, Kendrick, \& Maben, 1992), socioeconomic status (Knopf \& Mabel, 1975), and academic achievement (Campbell, D’Amato, Raggio, \& Stephens,
1991; Edley \& Knopf, 1987). Performance also is usually poorer among participants with clinical diagnoses of schizophrenia, ADHD, learning disability, brain injury, dementia, depression, and anxiety (Beale, Matthew, Oliver, \& Corballis, 1987; Chee, Logan, Schachar, Lindsay, \& Wachsmuth, 1989; Earle-Boyer, Serper, Davidson, \& Harvey, 1991; Goetsch \& Adams, 1990; Kaufmann, Fletcher, Levin, Miner, \& Ewing-Cobbs, 1993; Mirsky, et al., 1992; Parasuraman, Mutter, \& Molloy, 1991).

The third category of factors affecting vigilance performance includes environmental or situational conditions during task performance, such as noise, temperature, vibration, crowding, and other conditions. These environmental factors may either disrupt or facilitate performance depending on interactions with the type of task and participant characteristics (Ballard, 1996b; Broadbent \& Gregory, 1965; Hancock, 1984; McGrath, 1968; McGrath \& Hatcher, 1968; Warner \& Heimstra, 1972). Similarly, effects of both task parameters and environmental conditions may be seen for some participant groups, but not others (Deaton \& Parasuraman, 1993; Parasuraman \& Giambra, 1991; Schiff \& Knopf, 1985). Study of vigilance performance under various combinations of conditions is important in approximating "real-world" conditions, where interactions produce both additive and multiplicative effects.

Task, environment, and participant factors and their interactions also produce differential effects on different performance measures. For example, Ballard (1996b) found that more omissions, but not commissions, occurred with the combination of high anxiety, fast event-rate, and quiet, intermittent white noise. In other studies (see Parasuraman, 1998; Parasuraman, Warm, \& See, 1998), various factors diminished overall measures, but did not affect time-related decrements. These observations support a distinction between the overall vigilance level, reflected by averages of correct responses, error rates, or response latencies across the entire vigilance test, and the vigilance decrement, shown in the decline in performance over blocks of time or trials. Parasuraman contends that the overall level of vigilance is related to cortical arousal, while the 
vigilance decrement is not (see Parasuraman, 1984; Parasuraman et al., 1998). "Arousing" factors may therefore affect overall performance but not the vigilance decrement.

\section{Neuropsychological Models of Attention}

These differential effects are not surprising given a multifaceted view of "attention", as well as evidence that different aspects of attention have different neuroanatomical substrates. Various authors have developed neuroanatomic or neurochemical models that implicate specific pathways for different subtypes of attention. For example, Mesulam (1981) suggested the importance of parietal regions for spatial attention, frontal areas for planning and control, and brainstem pathways (the reticular system) for arousal and vigilance. Posner and Petersen (1990) and Posner and Raichle (1994) also identified three circuits important for different aspects of attention. In this model, the "orienting" circuit (parietal cortex, superior colliculus, and pulvinar) serves selective attention. An "executive control" circuit (anterior cingulate, left frontal cortex, and basal ganglia) helps to detect target stimuli, coordinate multiple subsystems of attention, and start and stop mental operations and responses. Finally, an "alerting" circuit (right-lateralized noradrenergic connections of the locus coerulus, right prefrontal cortex, and right parietal lobe) serves requirements for sustained attention, or vigilant readiness to respond. According to Parasuraman et al. (1998), research suggesting that right frontal/brainstem nuclei pathways underlie vigilance performance has typically used overall performance measures. Consequently, neuroanatomic pathways involved in the vigilance decrement are not well understood.

Mirsky, Anthony, Duncan, Ahearn, and Kellam (1991) identified four elements of attention, their likely neuroanatomical substrates, and the neuropsychological tests that measure each element. According to this model, the "focus-execute" element involves selection of target stimuli for processing. Tests requiring this element include Digit-Symbol Substitution, Stroop, Cancellation, and Trailmaking. Brain regions serving these functions include inferior parietal cortex, superior temporal cortex, and striatum. The "sustain" element, also known as vigilance, involves the capacity to maintain an attentional focus. It is measured by hits, commissions, and reaction time on the traditional CPT, and involves the tectum and mesopontine regions of the reticular formation. The "shift" element involves flexible adaptive changes in attentional focus, as required by the Wisconsin Card Sort. This element is supported by activity in the prefrontal cortex and anterior cingulate. The "encode" element involves the ability to hold information essential to processing in mind, as measured by the Digit Span and Arithmetic tasks from the Wechsler Intelligence Scales, and is supported by the hippocampus and corpus striatum. Mirsky et al. (1991) suggested that tasks requiring "controlled" processing employ the focus-execute, encode, and shift elements, while "automatic" processing may require only the sustain element.

Norman and Shallice $(1980,1986)$ also emphasized the distinction between automatic and controlled processing. These authors suggested that a supervisory attentional system is activated when executive control is needed rather than routine or automatic processes. According to this model, situations calling for "executive control" include those that involve planning or decisionmaking, error correction, novel or not-welllearned responses, conditions judged difficult or dangerous, and overcoming habitual responses. Posner and DiGirolamo (1998) argued that interference tasks such as the Stroop, response-inhibition tasks such as the generate-novel-uses task, and error-detection tasks require executive control. Performance of these types of tasks is associated with activation of the anterior cingulate and the left frontal cortex in PET and EEG studies (e.g., Pardo, Pardo, Janer, \& Raichle, 1990).

These models used somewhat different terminology and methodologies, but many of their conclusions are consistent. It therefore appears that connections between right frontal cortex and brainstem nuclei of the noradrenergic locus coerulus are important in overall vigilance levels, as measured by total errors or average response speed on traditional CPTs. Anatomical pathways for the vigilance decrement are less well understood. The connections of posterior parietal with "working memory" regions of the frontal lobe 
may be important for selective attention. Finally, the anterior cingulate and its connections may serve attentional functions that require "executive control," as in tasks requiring planning, novel responses, or inhibition of habitual responses.

Taken together, these observations confirm the view that sustained attention is only one part of the multifaceted construct of "attention," and that the measures derived from different attention tasks may indeed assess the functioning of different brain systems. If variations in task parameters require the activation of different brain systems, then tasks that differ on important parameters may be expected to produce different patterns of results, as well as different alterations in that pattern as a result of environmental or participant factors.

\section{The "MHS-Standard" Task}

Several CPT versions have been marketed for clinical use. Recently, Multi-Health Systems (MHS) marketed a computer program that produces traditional " $\mathrm{X}$ " and "AX" CPTs, as well as a new task in which participants press a key for any letter except " $\mathrm{X}$ ". This task, which MHS calls the "Standard CPT", is described in the manual (Conners, 1995) as more theoretically sound and more sensitive in detecting attention deficits than traditional tasks, but also as belonging to the same family of tests as traditional CPTs. Most of the research cited in the manual involved traditional " $\mathrm{X}$ " or "AX" versions of the CPT (see Conners, 1995, pp. 70-81).

Comparison of task parameters reveals that the MHS-Standard Task is indeed similar to traditional CPTs in many respects. The stimuli are capital letters presented sequentially on a computer screen. The response requirement is the simple motor response of pressing a computer key. The letter " $X$ " is the infrequent "critical signal" for which the participant must remain vigilant. The duration of the task (approximately 14 minutes) falls in the middle range of typical CPT paradigms. Although sensory-detection vigilance tasks often are much longer (e.g., the 2-hour "Clock Test" used in early research on sustained attention by Mackworth, 1950), traditional CPTs may be as brief as five minutes or less, and as lengthy as 30 minutes or more.
However, the parameters of the MHS-Standard differ from those of the traditional CPT in several ways. Most importantly, the "target stimuli" for which the participant must press the computer key includes all letters except "X". Consequently, the response required for the "critical signal" of " $X$ " is to withhold an ongoing motor response. This difference between the MHS-Standard and traditional CPTs raises several issues in interpreting results. Specifically, "omission errors" are defined on both tasks as failure to press the key at the appropriate time. On the traditional CPT, omission errors (failure to press the key when the " $X$ " appears) suggest an inability to detect the critical signal for which the participant was keeping a vigil, presumably because of a lapse of sustained attention. In contrast, on the MHSStandard, omission errors (failure to press the key when any letter other than " $X$ " appears) indicate a failure to maintain an ongoing, repetitive motor response. Similarly, "commission errors" on both tasks are defined as pressing the key at the incorrect time. On the traditional CPT, commission errors (pressing the key when " $\mathrm{X}$ " did not appear) suggest either impulsivity or sensory discrimination errors. In contrast, commission errors on the MHS-Standard (pressing the key when " $X$ " appears) suggest an inability to inhibit a habitual response. Because of these differences in the conceptual basis for "omission" and "commission" errors, difficulties also arise for the interpretation of measures derived from omission and commission rates, such as $d$ ' (perceptual sensitivity) and $\beta$ (response criterion). Hit reaction time measures also are affected by the definition of "target stimulus." On the traditional CPT, hit reaction time is the latency between onset of a critical signal ("X") and the required response (pressing the key). In contrast, hit reaction time on the MHS-Standard is the latency between onset of non-critical signals (any letter except " $\mathrm{X}$ ") and the required response (pressing the key). For the MHS-Standard, it is not possible to compute an average reaction time for correct responses to the critical signal of " $\mathrm{X}$ " (not pressing the key).

The difference in response requirements for the MHS-Standard also raises the possibility that good performance on the task requires the activity 
of different brain systems than those involved in traditional CPT performance. Specifically, because the participant must inhibit an established, habitual motor response, it may be that "executive" or "controlled" attention must be invoked, rather than "sustained" attention. If so, accurate performance on the MHS-Standard may require activity of the anterior cingulate and midline frontal cortex (see Mirsky et al., 1991; Pardo et al., 1990; Posner \& DiGirolamo, 1998; Posner \& Petersen, 1990; Posner \& Raichle, 1994). If sustained attention is not the central element of attention involved in performance of the MHSStandard, it may be that environment or participant variables related to "arousal" systems underlying vigilance performance will have little effect on performance of the MHS-Standard.

Other differences between the MHS-Standard and traditional CPTs also are noteworthy. Most evident is the variability of interstimulus intervals (ISI). Traditional CPTs usually maintain a constant ISI across the task. Between-task differences in ISI affect performance, and within-task variability of ISI can diminish performance when the ISI is unpredictable from one trial to the next (see Warm \& Jerison, 1984). In the MHS-Standard, each block of trials is divided into three randomly ordered sub-blocks of 1-sec, 2-sec, and 4-sec ISIs. Equal numbers of critical signals (" $X$ ") and background events (other letters) are presented within each sub-block. Like most CPTs, ISI is therefore confounded with task duration, so that sub-blocks with longer ISIs last for a greater proportion of total block time. Averaged across stimulus events, the mean ISI per block is about 2.3-sec. Averaged across time, however, the participant spends more time per block observing a slower presentation rate. Although the ISI is variable between sub-blocks of trials, within sub-blocks the ISI is predictable and therefore should not affect performance.

This combination of task parameters in the MHS-Standard produces a relatively slow event rate compared to traditional CPTs. If this were the only difference, more accurate performance might be expected on the MHS-Standard than on fast-event CPTs. However, the different response requirements may make the MHS-Standard a fundamentally different task.

\section{Hypotheses of the Present Study}

The present study compared the MHS-Standard with two versions of the traditional CPT. If the MHS-Standard is a member of the "family" of traditional CPTs, then performance on this task should be subject to the same effects of task, environmental, and participant variables as those demonstrated for traditional AX tasks. First, overall performance on the MHS-Standard should include greater speed, fewer omissions, and fewer "critical signal errors" than traditional CPTs because of task parameter differences. Specifically, the MHS-Standard has a slower average event rate, longer stimulus duration, higher probability of critical signals, higher ratio of targets to non-targets, higher response rate, and lower memory load requirements than the two AX tasks used in this study. Each of these parameters typically yields better overall performance on CPTs.

Second, if the MHS-Standard is a member of the traditional CPT family, then vigilance decrement functions should be susceptible to the same effects observed in previous research. Specifically, the slower event rate, longer stimulus duration, higher response rate, and higher critical signal rate should lead to a less pronounced decrement function than that of the fast-event, low-signal probability, traditional CPT used in the present study.

Finally, if the MHS-Standard can be considered the same type of task as traditional CPTs, then performance measures should be affected by the same environmental and participant variables. For example, participant anxiety and interactions with environmental noise conditions appear to affect performance primarily on fast-event-rate CPTs (Ballard, 1996b). In the present study, the patterns of effects of environmental noise and participant anxiety on performance of the MHSStandard should be similar to those obtained for the slow-event CPT-AX task.

In contrast, the response-inhibition requirement of the MHS-Standard task may constitute a fundamentally different task, which is perhaps served by different brain regions. If so, the pattern of performance of the MHS-Standard may differ from that on traditional CPTs in ways that cannot be explained fully by differences in other task 
parameters. These hypotheses were explored in the following multivariate, mixed factorial design.

\section{METHOD}

\section{Participants}

The sample consisted of 155 undergraduates (19 male and 136 female) who participated in a larger neuropsychological study for extra credit in their introductory psychology classes at a small, selective, northeastern public college. Nine participants were dropped from further analysis because they made no correct responses on at least one block of trials, which made computation of an average hit reaction time impossible. All nine were assigned to the fastevent-rate CPT, and all but one to quiet background noise. Chi-square and $t$-tests revealed that dropped participants made significantly more errors than remaining participants, and thus should be considered extreme cases. However, dropped participants did not differ significantly from remaining subjects in gender, age, class rank, ethnicity, first language, or time of testing (all $p \mathrm{~s}>.05$ ).

The remaining 146 participants included 18 males (12\%) and 128 females (88\%). Average age was 19.98 years $(S D=2.12)$. Class ranks included 26 first-year students, 43 sophomores, 52 juniors, and 25 seniors. Ethnicity included 135 whites (92.4\%), six Asians (4.1\%), three Hispanics (2.1\%), and two multi-racial individuals (1.4\%). English was the first language for 143 participants (98\%), and the United States was named as country of origin by 142 (97\%). Participants who needed corrective lenses (74\% of the sample) wore them during the task. No participants reported hearing deficits.

\section{Materials}

\section{Attention Tasks}

Three tasks were produced using Conners' Continuous Performance Test Computer Program, 3.0 (Conners, 1995). Two versions of the "AX" vigilance task differed primarily in event-rate and were comparable to tasks used in previous research (Ballard, 1996b). The third task was the MHSStandard. In all three tasks, randomly sequenced white capital letters (ABCDEFHILMNOTXYZ), $2.5 \mathrm{~cm}$ in height, were presented on a black background via a Zenith Systems 386 computer with a gray-scale monitor. Standard instructions were presented aloud by the experimenter while the same instructions appeared on the monitor. Participants pressed the spacebar to respond to targets. A 20second practice trial included two critical signals
("X"). Instructions were repeated for participants who made errors on the practice trial.

The MHS-Standard task is not modifiable in the CPT software. The pre-designed task includes six blocks of trials for a total task time of about 14 minutes. To equate the task duration of the three tasks, only the first four blocks of trials of the MHSStandard were included in analysis. The three tasks were approximately equivalent in task duration ( $\sim 10$ minutes), number of blocks (4), block duration $(\sim 2.5$ minutes $)$ and critical signals per block (5-6).

Table 1 compares other parameters of the three tasks. The "AX-slow" and "AX-fast" versions differed in total number of stimuli, inter-stimulus interval (ISI), and stimulus duration, yielding tasks that differed primarily in event rate. Both had an equal number of critical signals ("A followed by X") in each of four blocks of time. The required response for each of the $\mathrm{AX}$ tasks was to press the spacebar after the appearance of the critical signal. The critical signal therefore was also the "target" stimulus. The ratio of critical signals to total stimuli was reduced by half in the AX-fast task compared to the AX-slow task.

The critical signal in the MHS-Standard was "X", which occurred at a rate of $10 \%$ of total stimuli. However, the response requirement was to withhold the keypress when the critical signal appeared. The "target" stimuli were all letters except $X$, and the required response to targets was to press the spacebar. Therefore, the MHS-Standard may be considered a response-inhibition task. Compared to the AX-tasks, the MHS-Standard had fewer total stimuli. The ISI varied across three subblocks in each block of trials. Specifically, in each block of 60 stimuli, sub-blocks of 20 stimuli used either a 1-, 2-, or 4-second ISI. The order of the three ISIs was random within each block of trials, but consistent within each sub-block of 20 trials. On average, the event rate of the MHS-Standard was therefore slower than that of the AX-slow task.

Scores used in the first analysis included the following. Omission errors were defined as failure to press the spacebar when a target stimulus appeared. Commission errors were defined as pressing the spacebar when a non-target stimulus appeared. Because of differences in the total possible omissions and commissions across the three tasks, both types of error scores were converted to percentages. Hit reaction time was computed as the average latency in milliseconds between onset of a target stimulus and a correct press of the spacebar. Hit reaction time variability was computed as the standard error across all correct keypresses for target stimuli. 
Table 1. Comparison of Task Parameters for Two Versions of the Traditional CPT-AX Task ("Slow Event Rate" and "Fast Event Rate") and the "MHS-Standard" Task (Conners, 1995).

\begin{tabular}{|c|c|c|c|}
\hline Parameters: & $\begin{array}{l}\text { Traditional CPT: } \\
\text { "AX-Slow", }\end{array}$ & $\begin{array}{l}\text { Traditional CPT: } \\
\text { "AX-Fast" }\end{array}$ & $\begin{array}{l}\text { MHS-Standard } \\
\text { (first four blocks) }\end{array}$ \\
\hline Interstimulus Interval & $1 \mathrm{sec}$ & $.5 \mathrm{sec}$ & 1,2 , or $4 \mathrm{sec}$ \\
\hline ISI Variability & $\begin{array}{l}\text { Constant across all } \\
\text { trials }\end{array}$ & $\begin{array}{l}\text { Constant across all } \\
\text { trials }\end{array}$ & $\begin{array}{l}\text { Constant within } \\
\text { sets of } 20 \text { trials }\end{array}$ \\
\hline Average ISI & $1 \mathrm{sec}$ & $.5 \mathrm{sec}$ & $2.3 \mathrm{sec}$ \\
\hline Total \# of Stimull & 600 & 1200 & 240 \\
\hline \# Stimuli per Block & 150 & 300 & 60 \\
\hline Stimulus Duration & $200 \mathrm{~ms}$ & $200 \mathrm{~ms}$ & $250 \mathrm{~ms}$ \\
\hline \multicolumn{4}{|l|}{ "Critical Signals" } \\
\hline Definition & $\mathrm{X}(\operatorname{after} \mathrm{A})$ & $\mathrm{X}(\operatorname{after} \mathrm{A})$ & $X$ \\
\hline Total Number & 20 & 20 & 24 \\
\hline Number per Block & 5 & 5 & 6 \\
\hline Rate & $1: 30(3.33 \%)$ & $1: 60(1.67 \%)$ & $1: 10(10 \%)$ \\
\hline Response Required & $\begin{array}{l}\text { Initiate motor } \\
\text { response (keypress) }\end{array}$ & $\begin{array}{l}\text { Initiate motor } \\
\text { response (keypress) }\end{array}$ & $\begin{array}{l}\text { Inhibit ongoing } \\
\text { motor response }\end{array}$ \\
\hline \multicolumn{4}{|l|}{ "Targets", } \\
\hline Definition & $\mathrm{X}(\operatorname{after} \mathrm{A})$ & $X($ after A) & Any letter except $\mathrm{X}$ \\
\hline Total Number & 20 & 20 & 216 \\
\hline Number per Block & 5 & 5 & 216 \\
\hline Rate & $3.33 \%$ & $1.67 \%$ & $90 \%$ \\
\hline Response Required & Press spacebar & Press spacebar & Press spacebar \\
\hline \multicolumn{4}{|l|}{ "Non-Targets" } \\
\hline Definition & Any letter except $\mathrm{X}$ & Any letter except $\mathrm{X}$ & $\mathrm{X}$ \\
\hline Total Number & 580 & 1180 & 24 \\
\hline Number per Block & 145 & 295 & 6 \\
\hline Rate & $96.67 \%$ & $98.33 \%$ & $10 \%$ \\
\hline Response Required & Do not press key & Do not press key & Do not press key \\
\hline
\end{tabular}

Note. CPT $=$ Continuous Performance Test; ISI $=$ Inter-Stimulus Interval.

For the second analysis, critical errors were defined as incorrect responses to the critical signal of "X." For the AX-slow and AX-fast tasks, critical errors were failures to press the spacebar when "A" was followed by " $\mathrm{X}$ ". For the MHS-Standard task, critical errors were failures to withhold the keypress when " $X$ " appeared.

\section{Anxiety Measure}

The State/Trait Anxiety Inventory, Form Y (STAI-Y; Spielberger, Gorsuch, Lushene, Vagg, \& Jacobs, 1983) was administered before performance of the computer task to identify high- and low-anxious groups. On the 20-item "Trait Anxiety" scale, participants use a 4-point response scale to rate how often they experience the feelings described in each item. Approximately half the items are reverse-scored so that higher scores indicate higher anxiety levels. Item scores are summed to yield a total score that can range from 20 to 80 . Reliability and validity of this measure have been extensively investigated by previous authors, with results indicating strong internal consistency and test-retest reliability (Spielberger, Vagg, Barker, Donham, \& Westberry, 1980; Spielberger, et al., 1983). For the purpose of the present study, total scores on the Trait Anxiety scale were dichotomized via median split to form an Anxiety Factor with two levels: high-anxious and low-anxious.

\section{Noise Generator}

A Marsona 1200 sound conditioner generated noise during the CPT. Level of noise was set at either high volume $(\sim 90 \mathrm{~dB})$ or low volume $(\sim 30 \mathrm{~dB})$, and the constancy of noise was set to generate either fluctuating waves of static ("surf") or constant white noise ("rain"). In the fluctuating noise condition, waves of noise peaked at the maximum assigned 
volume (30 or $90 \mathrm{~dB}$ ) and trailed off at irregular intervals to barely perceptible levels. The ratio of noise-on to noise-off was approximately $60 \%$ in these "surf" conditions.

\section{Procedure}

Testing times were spread relatively evenly throughout the day from 8:30 am to $4: 00 \mathrm{pm}$ on weekdays only. At individually scheduled times, participants met with one of five trained experimenters, who conducted each phase of the investigation. For each step in the procedure, standardized instructions were read verbatim to participants, and CPTs were administered in a partially soundproof, dimly illuminated room. Experimenters were not blind to experimental conditions, but were unaware of anxiety scores until after the individual participated. At each participant's arrival, informed consent was obtained. Demographic information was collected and the "trait" section of the STAI was administered. Participants were then escorted to the cubicle to complete the assigned computer task in the assigned noise condition. During the task, the experimenter sat out of the participant's sight in a room adjoining the cubicle. Participants were debriefed about the general purposes of the study and were treated at all times in accordance with the American Psychological Association's ethical guidelines.

\section{RESULTS}

\section{Plan of Analysis}

Two Between/Within Multivariate Analyses of Variance (MANOVA) were planned. In the first, dependent measures were omissions (\%), commissions (\%), mean hit reaction time, and reaction time variability. The second analysis used critical errors as the single dependent variable. In each analysis, Blocks of Trials served as the repeatedmeasures factor. Between-subjects factors included experimentally manipulated variables of Task Type (AX-slow, AX-fast, or MHS-Standard), Noise Constancy (constant or fluctuating), and Noise Volume (quiet-30dB and loud-90dB), as well as the subject factor of Trait Anxiety (high-anxious or low-anxious). The resulting $4 \times 3 \times 2 \times 2 \times 2$ mixed MANOVAs were conducted using the Type III (Regression) sum of squares, an SPSS-WINDOWS procedure that is useful for unequal cell sizes. Multivariate effects were examined first, followed by univariate effects of the multivariate-significant factors. Tukey's HSD was used to evaluate cell differences. Effects were considered significant at the .05 level, but near-significant trends $(p<.10)$ also were noted.

\section{Preliminary Examination of the Data}

In preliminary data analysis, scatterplots revealed no curvilinear relationships between continuous variables. Descriptive statistics, shown in Table 2, revealed that anxiety scores were normally distributed. However, positive skew and kurtosis were found for all CPT measures. Such distributions are typical in studies of normal adults, who usually perform CPT tasks quickly and accurately. Therefore, significant effects of factors on CPT scores were retested using non-parametric methods. Results were confirmed in each case, and are not reported here.

\section{Comparison of Performance on the MHS- Standard and Two CPT-AX Tasks}

The first analysis examined effects of task type, noise constancy, noise volume, and trait anxiety on task performance across blocks of trials. Dependent measures were omissions (\%), commissions (\%), hit reaction time, and reaction time variability. Mauchly's W was significant for each DV, indicating a violation of the sphericity assumption. Therefore, degrees of freedom were adjusted using Greenhouse-Geisser epsilon. Resulting multivariate and univariate $F$-values are presented in Table 3. In the sections below, between-subjects multivariate and univariate effects are presented first. Because these effects were based on averages across blocks of trials, they may be considered measures of the overall vigilance level. Next, repeated-measures multivariate and univariate effects are presented. These effects, which are within-subjects comparisons over blocks of trials, may be considered measures of the vigilance decrement.

\section{Overall Vigilance}

As shown in Table 3, significant multivariate effects of between-groups factors included the main effect of Task Type, the two-way interaction of Volume X Anxiety, and the three-way interac- 
Table 2. Descriptive Statistics for Full Sample on Trait Anxiety and CPT Performance Measures by Blocks of Trials (Percent of Targets for Which Omission Errors Were Made, Percent of Non-Targets for Which Commission Errors Were Made, Average Reaction Time for Correct Keypresses, Variability of Reaction Time, and Critical Error Frequency). [ $N=146]$.

\begin{tabular}{|c|c|c|c|c|c|c|c|}
\hline \multicolumn{2}{|l|}{ Variables } & Mean & $(S D)$ & Min. & Max. & Skew & Kurtosis \\
\hline \multicolumn{2}{|c|}{ Participant Pretest Trait Anxiety: } & 37.32 & $(8.25)$ & 21 & 63 & .52 & -.01 \\
\hline \multicolumn{8}{|c|}{ CPT Performance: } \\
\hline \multirow[t]{4}{*}{ Omissions \%: } & Block 1 & 1.77 & (5.98) & 0 & 40.00 & 3.78 & 15.12 \\
\hline & Block 2 & 2.57 & $(-7.37)$ & 0 & 40.00 & 3.10 & 9.70 \\
\hline & Block 3 & 2.91 & $(7.77)$ & 0 & 40.00 & 2.73 & 7.23 \\
\hline & Block 4 & 2.52 & (7.38) & 0 & 40.00 & 3.10 & 9.71 \\
\hline \multirow[t]{4}{*}{ Commissions \%: } & Block 1 & $(1.25)$ & 2.81 & 0 & 16.67 & 3.03 & 10.20 \\
\hline & Block 2 & .74 & (1.93) & 0 & 11.11 & 3.21 & 10.90 \\
\hline & Block 3 & 1.04 & (2.14) & 0 & 11.11 & 2.24 & 4.82 \\
\hline & Block 4 & 1.15 & $(2.41)$ & 0 & 11.11 & 2.49 & 5.99 \\
\hline \multirow[t]{4}{*}{ Hit Reaction Time (ms): } & Block 1 & 413.23 & (90.63) & 274 & 782 & .19 & 1.99 \\
\hline & Block 2 & 436.64 & $(103.40)$ & 282 & 990 & 1.95 & 6.41 \\
\hline & Block 3 & 434.16 & (91.34) & 294 & 770 & 1.48 & 2.85 \\
\hline & Block 4 & 428.10 & (85.93) & 280 & 800 & 1.44 & 3.93 \\
\hline \multirow[t]{4}{*}{ Hit RT Standard Error: } & Block 1 & 20.87 & (16.26) & .00 & 104.25 & 2.54 & 9.03 \\
\hline & Block 2 & 22.40 & (17.84) & .00 & 119.75 & 2.76 & 9.76 \\
\hline & Block 3 & 20.82 & (14.65) & .00 & 87.75 & 2.16 & 5.62 \\
\hline & Block 4 & 20.23 & (13.32) & .00 & 68.41 & 1.31 & 1.48 \\
\hline \multirow[t]{4}{*}{ Mean \# Critical Errors: } & Block 1 & .50 & $(1.01)$ & 0 & 6 & 2.87 & 9.75 \\
\hline & Block 2 & .36 & $(.71)$ & 0 & 4 & 2.46 & 7.01 \\
\hline & Block 3 & .49 & $(.78)$ & 0 & 4 & 1.70 & 2.93 \\
\hline & Block 4 & .51 & $(.85)$ & 0 & 4 & 2.04 & 4.33 \\
\hline
\end{tabular}

Note. CPT $=$ Continuous Performance Test.

tion of Task X Volume X Anxiety. Figure 1 shows that the main effect of Task Type strongly affected all four of the dependent measures averaged across blocks. Specifically, a significantly greater percentage of omissions was produced by the "AX-fast" task $(M=6.598 ; S E=.589)$ than by either the "AX-slow" $(M=.428 ; S E=.567)$ or the MHS-Standard $(M=.242 ; S E=.538)$. In contrast, the percentage of commissions was significantly greater on the MHS-Standard $(M=2.649$; $S E=.212)$ than on either the "AX-slow" $(M=.171 ; S E=.224)$ or the "AX-fast" task $(M=.042 ; S E=.233)$. Mean hit reaction time was significantly faster on the "AX-fast" $(M=389.645 ; S E=13.002)$ than on the MHSStandard $(M=420.112 ; S E=11.879)$, but was slowest for the "AX-slow" task $(M=467.221$; $S E=12.507)$. Variability in reaction time was greater on the "AX-Slow" $(M=30.233 ; S E=$ 1.258) compared to both the "AX-Fast" $(M=$
19.756; $S E=1.307)$ and the MHS-Standard $(M=13.280 ; S E=1.195)$.

Omissions differed further depending on the two-way interaction of Volume X Anxiety. In quiet noise, low-anxious participants produced significantly more omissions $(M=3.81 ; S E=$ $.59)$ than did high-anxious participants $(M=.91$; $S E=.72$ ). In contrast, with loud noise, lowanxious participants made fewer omissions $(M=2.22 ; S E=.69)$ than did high-anxious participants $(M=2.75 ; S E=.59)$. However, the significant three-way interaction of Task X Volume $\mathrm{X}$ Anxiety, shown in Figure 2, revealed that this pattern was applicable only to the two traditional CPT-AX tasks. Participants performing the MHSStandard showed no differences in omission rates for different combinations of noise volume and participant anxiety.

A similar three-way interaction effect of Task X Volume X Anxiety was found for the 
Table 3. Multivariate and Univariate F-Values From a $4 \times 3 \times 2 \times 2 \times 2$ Mixed MANOVA With Between-Subjects Factors of Task Type (T), Noise Constancy (NC), Noise Volume (V), and Participant Trait Anxiety (A), and a Repeated-Measures Factor of Blocks of Trials (B) as Predictors. CPT Performance Measures Were Outcome Variables. $[N=146]$.

\begin{tabular}{|c|c|c|c|c|c|}
\hline DVs: & $\begin{array}{l}\text { Multivariate } \\
\text { (Wilk’s } \\
\text { Lambda) }\end{array}$ & $\begin{array}{l}\text { Omission } \\
\text { Errors } \\
\text { (Percent) }\end{array}$ & $\begin{array}{c}\text { Commission } \\
\text { Errors } \\
\text { (Percent) }\end{array}$ & $\begin{array}{c}\text { Hit } \\
\text { Reaction } \\
\text { Time }\end{array}$ & $\begin{array}{l}\text { Hit RT } \\
\text { Standard } \\
\text { Error }\end{array}$ \\
\hline \multicolumn{6}{|l|}{ Between-Grp Factors: } \\
\hline Task & $37.578 * * *$ & $55.166^{* * *}$ & $54.865 * * *$ & $3494.83 * * *$ & $48.263 * * *$ \\
\hline Noise Constancy & 1.843 & .874 & 1.344 & .858 & .353 \\
\hline Volume & .571 & .037 & .098 & 1.026 & 1.223 \\
\hline Trait Anxiety & 1.354 & $3.296^{\text {tr }}$ & .837 & .152 & .497 \\
\hline $\mathrm{T} \times \mathrm{NC}$ & 1.043 & 1.700 & .472 & 1.497 & .685 \\
\hline $\mathrm{T} \times \mathrm{V}$ & .712 & .033 & .187 & .444 & $2.316^{\mathrm{tr}}$ \\
\hline $\mathrm{T} \times \mathrm{A}$ & 1.041 & $2.794^{\mathrm{tr}}$ & .214 & .457 & .708 \\
\hline $\mathrm{NC} \times \mathrm{V}$ & .086 & .078 & .000 & .116 & .239 \\
\hline $\mathrm{NC} \times \mathrm{A}$ & .732 & 1.129 & .428 & .004 & 1.816 \\
\hline $\mathrm{V} \times \mathrm{A}$ & $3.021 *$ & $6.960 * *$ & 1.596 & .326 & 1.551 \\
\hline $\mathrm{T} \times \mathrm{NC} \times \mathrm{V}$ & .233 & .086 & .630 & .168 & .239 \\
\hline $\mathrm{T} \times \mathrm{NC} \times \mathrm{A}$ & .616 & .352 & 1.778 & .162 & .241 \\
\hline $\mathrm{T} \times \mathrm{V} \times \mathrm{A}$ & $2.471^{*}$ & $4.440 *$ & $3.987 *$ & .067 & .511 \\
\hline $\mathrm{NC} \times \mathrm{V} \times \mathrm{A}$ & 1.609 & .820 & .216 & .938 & $4.603 *$ \\
\hline $\mathrm{T} \times \mathrm{NC} \times \mathrm{V} \times \mathrm{A}$ & .848 & .442 & 1.332 & .005 & 1.330 \\
\hline Within-Grp Factors: Block & $2.795^{*}$ & .863 & $2.040^{\operatorname{tr}}$ & $7.918 * * *$ & 1.086 \\
\hline $\mathrm{B} \times \mathrm{T}$ & $1.527 *$ & 1.123 & $2.091^{\operatorname{tr}}$ & $1.851^{\mathrm{tr}}$ & 694 \\
\hline $\mathrm{B} \times \mathrm{NC}$ & .492 & .209 & .446 & .461 & .680 \\
\hline $\mathrm{B} \times \mathrm{V}$ & .600 & .685 & 1.300 & .028 & .311 \\
\hline $\mathrm{B} \times \mathrm{A}$ & .342 & .130 & .151 & .896 & .102 \\
\hline $\mathrm{B} \times \mathrm{T} \times \mathrm{NC}$ & .969 & .154 & .478 & $2.401 *$ & .460 \\
\hline $\mathrm{B} \times \mathrm{T} \times \mathrm{V}$ & .834 & .703 & 1.090 & .449 & 1.261 \\
\hline $\mathrm{B} \times \mathrm{T} \times \mathrm{A}$ & .665 & .267 & .215 & 1.566 & .603 \\
\hline $\mathrm{B} \times \mathrm{NC} \times \mathrm{V}$ & .586 & .943 & .530 & .097 & .720 \\
\hline $\mathrm{B} \times \mathrm{NC} \times \mathrm{A}$ & .669 & .223 & .036 & .235 & $2.378^{\operatorname{tr}}$ \\
\hline $\mathrm{B} \times \mathrm{V} \times \mathrm{A}$ & .279 & .324 & .176 & .381 & .327 \\
\hline $\mathrm{B} \times \mathrm{T} \times \mathrm{NC} \times \mathrm{V}$ & 1.007 & 1.589 & .410 & .108 & .576 \\
\hline $\mathrm{B} \times \mathrm{T} \times \mathrm{NC} \times \mathrm{A}$ & .389 & .459 & .035 & .099 & .920 \\
\hline $\mathrm{B} \times \mathrm{NC} \times \mathrm{V} \times \mathrm{A}$ & .479 & .127 & .928 & .523 & .353 \\
\hline $\mathrm{B} \times \mathrm{T} \times \mathrm{NC} \times \mathrm{V} \times \mathrm{A}$ & .963 & .155 & .872 & .766 & .343 \\
\hline
\end{tabular}

Note. $\mathrm{CPT}=$ Continuous Performance Test $\mathrm{RT}=$ Reaction Time. Degrees of freedom were adjusted for violations of the sphericity assumption using Greenhouse-Geisser epsilon.

$* * *=p<.001 ; * *=p<.01 ; *=p<.05 ;{ }^{\text {tr }}=$ near-significant $(p<.10) F$-values.

percentage of commission errors. However, as shown in Figure 3, this effect was nearly the reverse of that for omission errors. Specifically, on only the MHS-Standard task, low-anxious participants made fewer commissions in quiet than in loud noise, while high-anxious participants made fewer commissions in loud noise than in quiet.

\section{Vigilance Decrement}

Significant multivariate effects of repeated-measures factors included the main effect of Block and the two-way interaction of Block X Task. The multivariate Block effect was produced by univariate effects on Hit Reaction Time and Commissions Percentage. The main effect of Block on hit reaction time yielded significant 

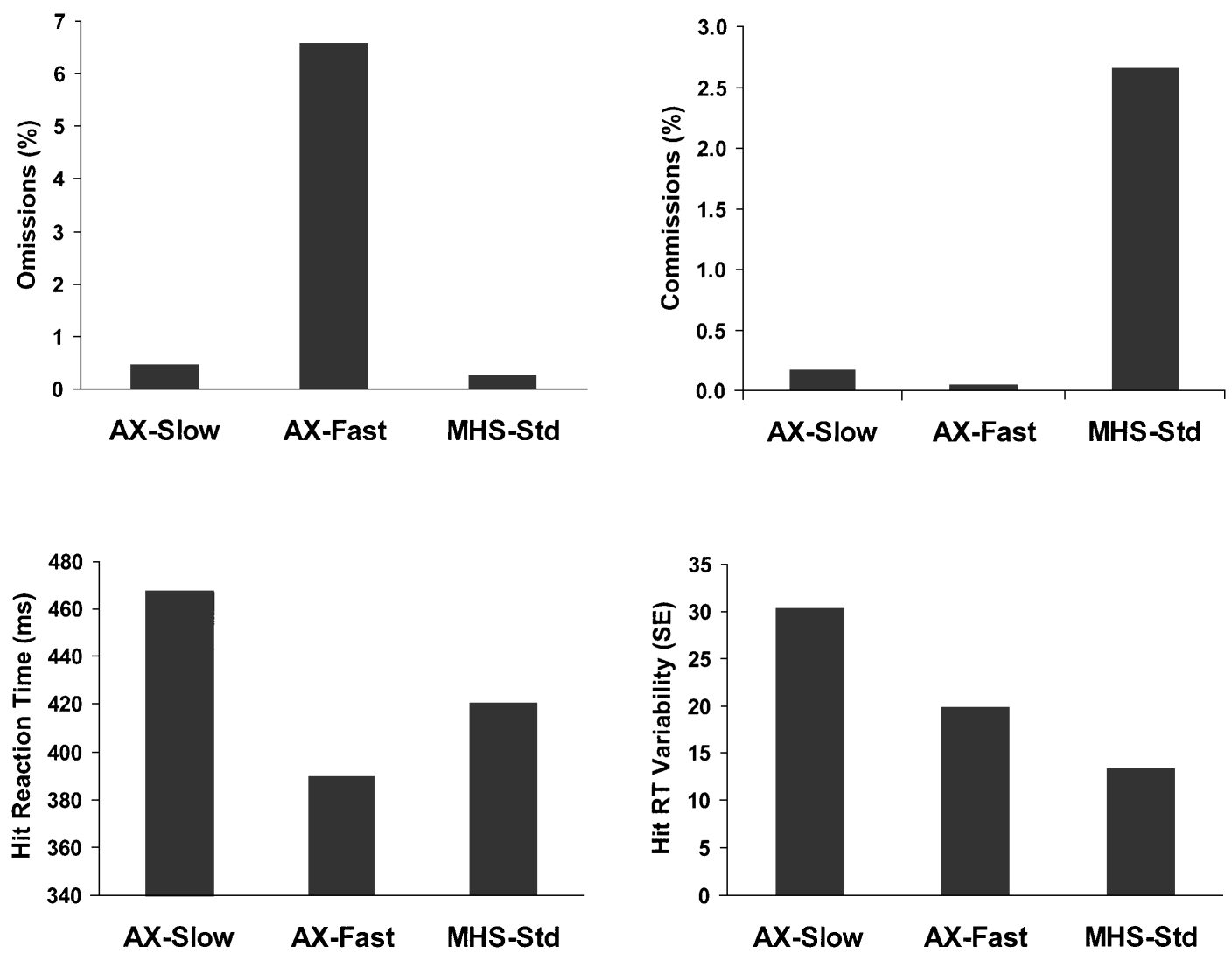

Fig. 1. Main effect of Task Type on four task performance measures: (A) Percent of targets to which the subject failed to respond (omission errors); (B) Percent of non-targets to which the participant incorrectly responded; (C) Mean reaction time (milliseconds) for correct responses (hits); (D) Mean variability (standard error) of hit reaction times. $[\mathrm{AX}-\mathrm{Slow}=$ slow event-rate traditional CPT; AX-Fast $=$ fast event-rate traditional CPT; MHS-Std = Multi-Health Systems "Standard" Task].

slowing from Block $1(M=410.00 ; S E=7.88)$ to Block $2(M=433.89 ; S E=8.92)$, with only slight improvement on Blocks $3 \quad(M=433.47$; $S E=7.63)$ and $4(M=425.28 ; S E=7.41)$. However, the Block $X$ Task interaction, shown in Figure 4 , revealed that hit reaction time slowed initially on all three tasks, with improvement over the last two trials seen only in the MHS-Standard task.

In contrast, the univariate effect of Block on commissions percentage produced improvement (decrease in commissions) from Block $1(M=$ $1.14 ; S E=.22)$ to Block $2(M=.69 ; S E=.15)$, with a subsequent increase across Blocks $3(M=$ $.91 ; S E=.16)$ and $4(M=1.08 ; S E=.61)$ to levels near that of Block 1. Again, however, the Block X
Task interaction, shown in Figure 5, revealed that commissions did not change across trials for the two traditional CPT tasks. Instead, the pattern of improvement on Block 2 and subsequent decline was seen only on the MHS-Standard task.

Comparison of "Critical Errors" on the MHSStandard and Two CPT-AX Tasks

For the second MANOVA, only the measure of "critical signal errors" was used as a dependent variable. As described above, "critical signal errors" were defined as errors in response to the critical signal of " $X$." On the two traditional CPT tasks, a critical signal error involves failure to press the spacebar when the critical signal appears. In contrast, a critical signal error on the 


\section{A. AX-Slow}

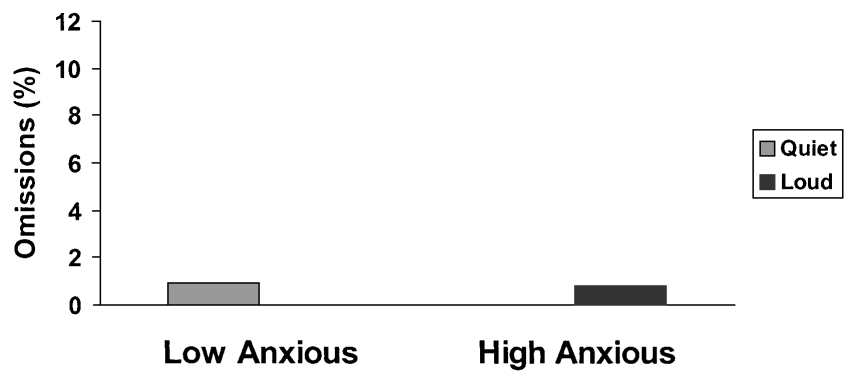

\section{B. AX-Fast}

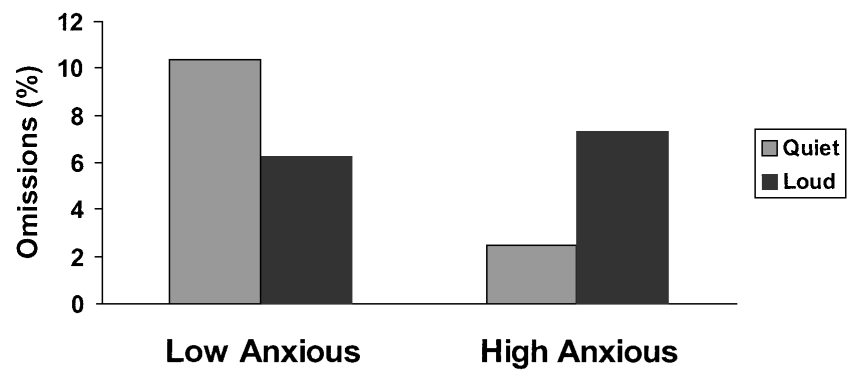

\section{MHS-Standard}

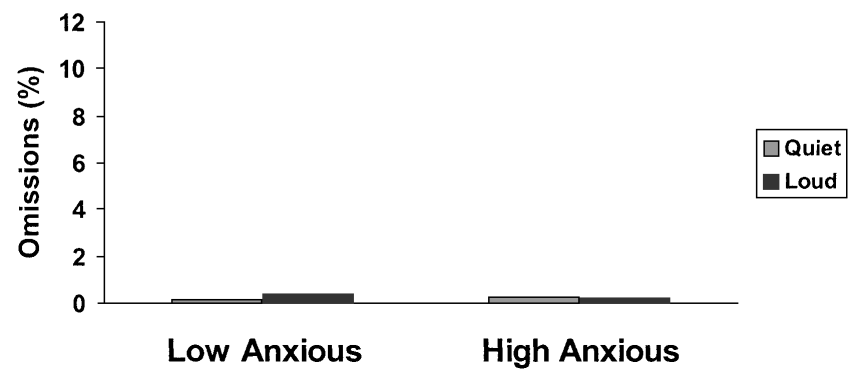

Fig. 2. Three-way interaction effect of trait anxiety (high or low), volume of environmental noise (quiet $30 \mathrm{~dB}$ or loud $90 \mathrm{~dB}$ ), and task type on percent of targets to which the participant failed to respond (omission errors): (A) Slow event-rate traditional CPT; (B) Fast event-rate traditional CPT; (C) Multi-Health Systems "Standard" Task.

MHS-Standard task involves failure to stop pressing the spacebar when the critical signal appeared. For this MANOVA, the sphericity assumption was not violated.

\section{Overall Vigilance}

The total number of critical signal errors differed significantly across the three tasks. As shown in
Figure 6, the main effect of task type produced significantly more critical signal errors in the AXfast $(M=.330 ; S E=.079)$ than in the AX-slow task $(M=.021 ; S E=.076)$, but significantly more critical signal errors were made on the MHSStandard $(M=.954 ; S E=.072)$ than on either of the two traditional CPTs, $F(2,122)=41.66$, $p<.001$. The Task X Volume X Anxiety interac- 


\section{A. AX-Slow}

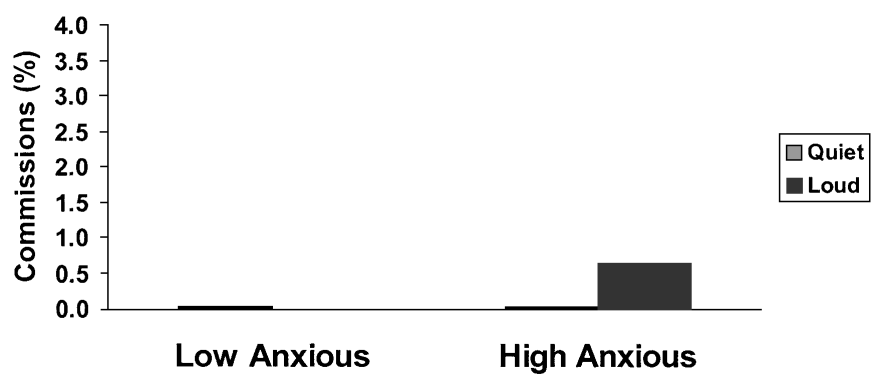

B. AX-Fast

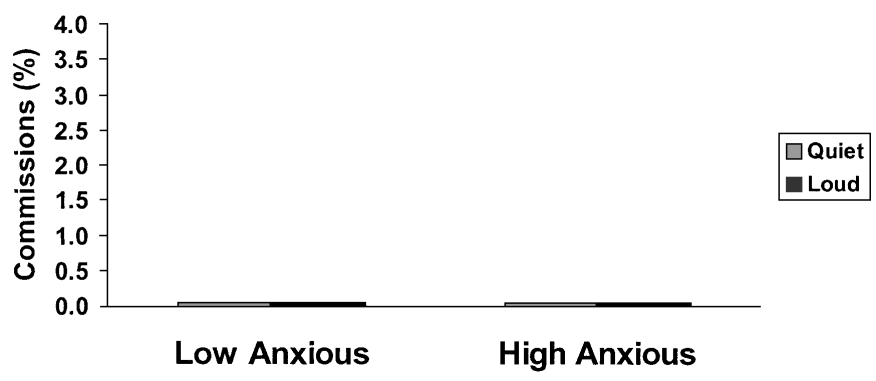

\section{MHS-Standard}

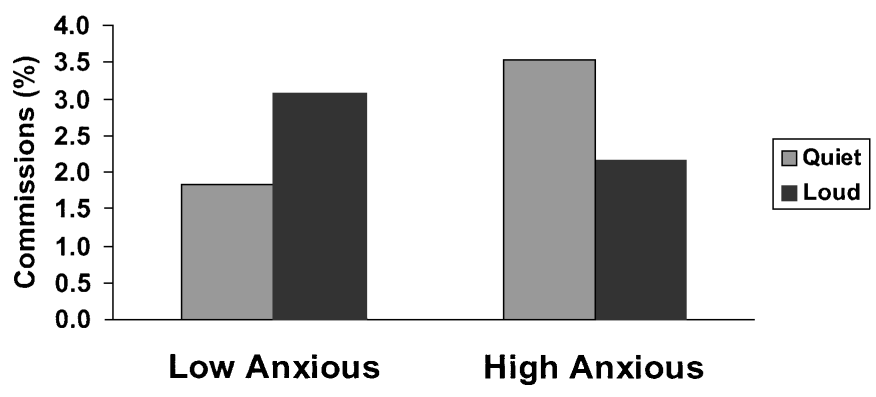

Fig. 3. Three-way interaction effect of trait anxiety (high or low), volume of environmental noise (quiet $30 \mathrm{~dB}$ or loud $90 \mathrm{~dB}$ ), and task type on percent of non-targets to which the participant incorrectly responded (commission errors): (A) Slow event-rate traditional CPT; (B) Fast event-rate traditional CPT; (C) MultiHealth Systems "Standard” Task.

tion contributed to additional significant betweensubjects effects on critical signal errors, $F(2$, $122)=5.87, p<.01$. Figure 7 shows that lowanxious participants made more errors on the AX-fast task in quiet noise, but more errors on the MHS-Standard task in loud noise. In contrast, the pattern for high-anxious participants was reversed, with more critical signal errors on AX- fast in loud noise, but more on the MHS-Standard in quiet conditions.

Only one within-groups effect was significant. The Block X Task interaction effect, shown in Figure 8, indicated a significantly different pattern of performance across blocks for participants performing the three different tasks, $F(6,366)=$ $2.27, p=.036$. Little change occurred on the AX- 


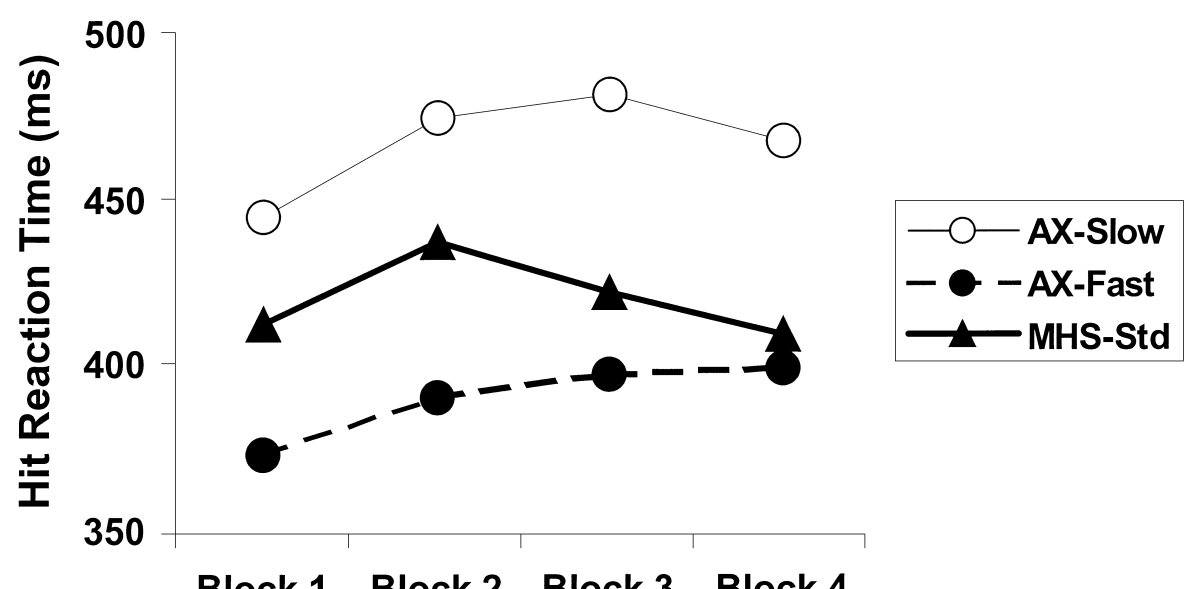

Fig. 4. Repeated-measures interaction effect of block and task type on mean hit reaction time (milliseconds). $[\mathrm{AX}-\mathrm{Slow}=$ slow event-rate traditional $\mathrm{CPT}$; AX-Fast $=$ fast event-rate traditional CPT; MHSStd = Multi-Health Systems "Standard" Task].

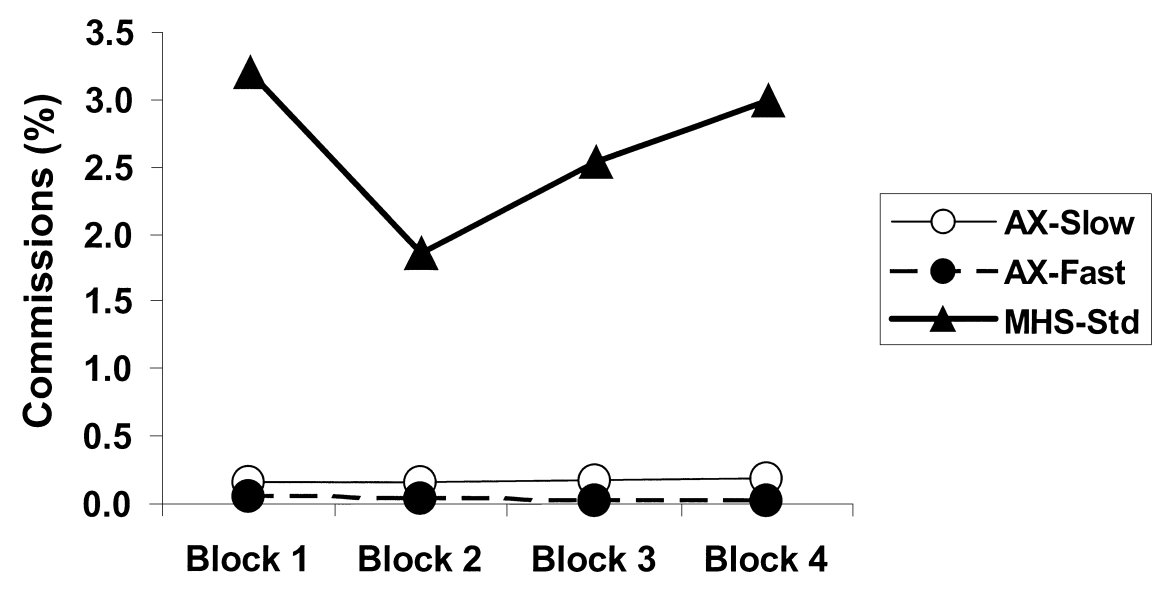

Fig. 5. Repeated-measures interaction effect of block and task type on percent of non-targets to which the participant incorrectly responded (commission errors). [AX-Slow $=$ slow event-rate traditional CPT; AXFast $=$ fast event-rate traditional CPT; MHS-Std = Multi-Health Systems "Standard" Task].

slow task, for which critical signal errors were near zero on all four blocks. On the AX-fast task, critical signal errors increased from Block 1 to Block 2, with little additional change on Blocks 3 and 4. This pattern is similar to the expected vigilance decrement function. However, on the MHS-Standard, the number of critical signal errors dropped significantly from Block 1 to Block 2. The subsequent decline in performance on the MHS-Standard (increase in critical signal errors) gradually approached but did not reach the error rate on Block 1.

\section{DISCUSSION}

The purposes of this paper were to compare task parameters of the MHS-Standard (Conners, 1995) with those of traditional CPTs, and to examine differences in effects of task parameters, environmental noise, and participant anxiety on performance of such tasks. Although the MHS-Standard is similar to traditional CPTs in some respects, it differs from traditional CPTs on several important dimensions. Specifically, the MHS-Standard includes a higher proportion of "targets" to 


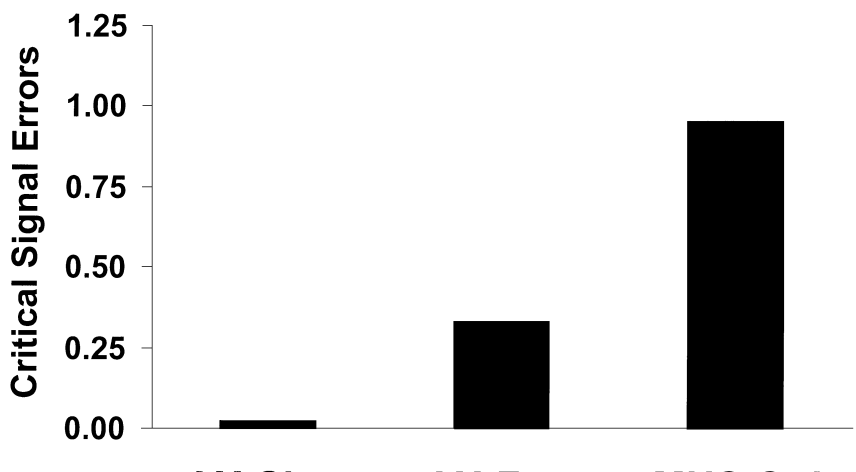

\section{AX-Slow AX-Fast MHS-Std}

Fig. 6. Main effect of Task Type on number of critical signal errors (incorrect responses to the letter "X"). [AXSlow $=$ slow event-rate traditional CPT; AX-Fast $=$ fast event-rate traditional CPT; MHS-Std $=$ MultiHealth Systems "Standard" Task].

which the participant must respond by pressing a key (90\% of stimuli), as well as a relatively high proportion of infrequently appearing "critical signals" (10\% of stimuli) for which the participant maintains a vigil. The average background event rate is slow compared to most traditional CPTs. The critical signal is a single letter (" $\mathrm{X}$ ") rather than a sequence (such as "AX"), with a concomitant reduction in memory load. The interstimulus interval (ISI) changes across blocks of trials, but is constant and therefore predictable within sub-blocks. The task characteristics of slow event rate, high response rate (due to high proportion of targets), relatively high probability of critical signals, and predictability of ISI are typically associated with fewer errors, faster reaction time, and less decrement in performance over time.

However, the MHS-Standard also differs from traditional CPTs in the response required when a "critical signal" is detected. Specifically, to perform well on the MHS-Standard, the participant must establish an on-going, repetitive motor response (pressing the key for any letter except $\mathrm{X})$ and then inhibit the ongoing response when the critical signal ("X") appears. The task therefore may involve "response-inhibition" rather than simple vigilance. Recent models of brain systems of attention suggest that the ability to inhibit habitual responses may depend on the anterior cingulate and its connections (Parasuraman et al., 1998; Pardo et al., 1990; Posner \& DiGirolamo, 1998; Posner \& Petersen, 1990; Posner \& Raichle,
1994), while the ability to sustain attention as measured by traditional CPTs may depend primarily on connections between brainstem nuclei (locus coeruleus) and right frontal cortex (Mirsky et al., 1991; Parasuraman et al., 1998). Given these distinctions, MHS-Standard performance may differ from that on traditional CPTs in ways that are not expected based on task parameter differences alone.

In support of the latter possibility, the present study revealed performance differences between the MHS-Standard, a slow-event CPT-AX task, and a fast-event CPT-AX task, suggesting that the MHS-Standard cannot be considered a member of the same "family of tests" as the traditional CPT. Given the differences in parameters on these three tasks, overall performance on the MHS-Standard task included higher response omission error rates than expected, higher critical signal error rates than expected, slower mean response times than expected, and less variability in response times than expected. Furthermore, the decrement function, which usually occurs early in a vigil for both error rates and speed, showed a different pattern on the MHS-Standard. In fact, performance improved significantly from Block 1 to Block 2, with reductions in both commission and omission rates. In contrast, response speed was reduced from Block 1 to Block 2, but increased again in Blocks 3 and 4.

Taken together, these differences from expected patterns of performance suggest that the 


\section{A. AX-Slow}

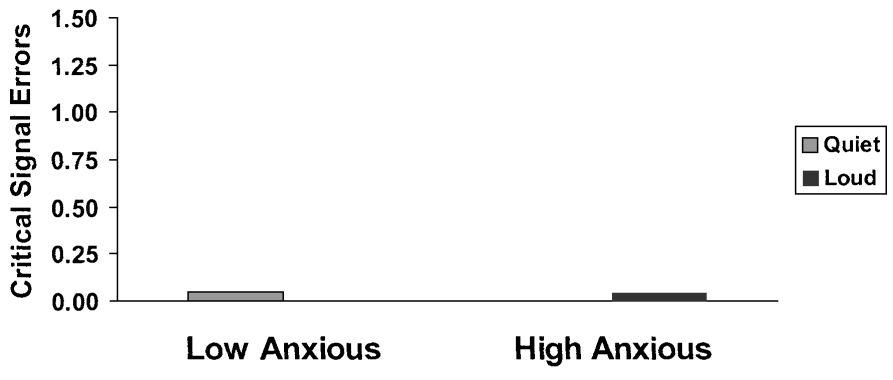

\section{B. AX-Fast}

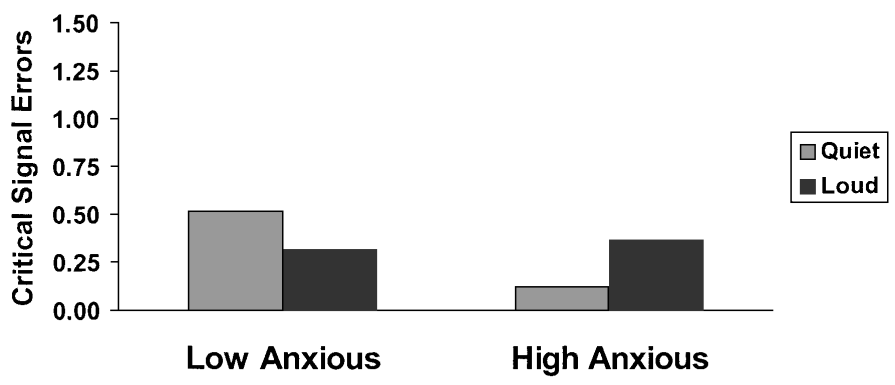

C. MHS-Standard

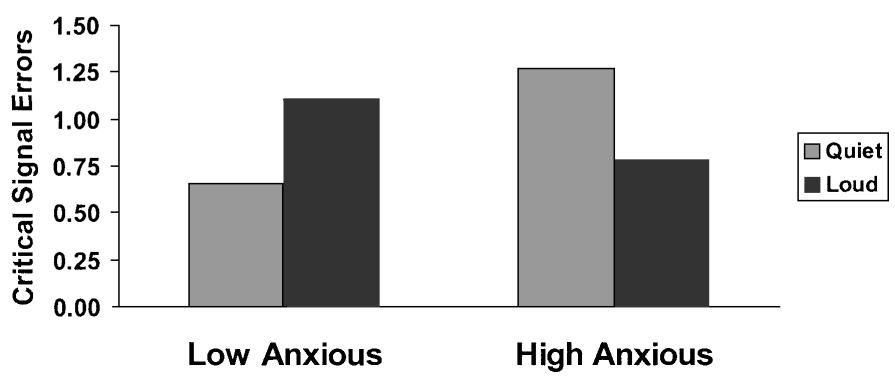

Fig. 7. Three-way interaction effect of trait anxiety (high or low), volume of environmental noise (quiet $30 \mathrm{~dB}$ or loud $90 \mathrm{~dB}$ ), and task type on number of critical signal errors (incorrect responses to the letter "X"): (A) Slow event-rate traditional CPT; (B) Fast event-rate traditional CPT; (C) Multi-Health Systems "Standard" Task.

MHS-Standard may constitute a measure of learning, or of the "executive control" of attention, rather than of the ability to sustain attention in a monotonous task (see Posner \& DiGirolamo, 1998). On early blocks of trials, the participant must learn to establish an appropriate response speed across variations in ISI, as well as to inhibit an ongoing response at the appearance of the critical signal. Participants therefore may slow their response speeds as they learn to inhibit incorrect responses, and then may speed up again as the inhibition becomes more "automatic" for the individual. If so, the task may prove useful in measuring aspects of executive control of atten- 


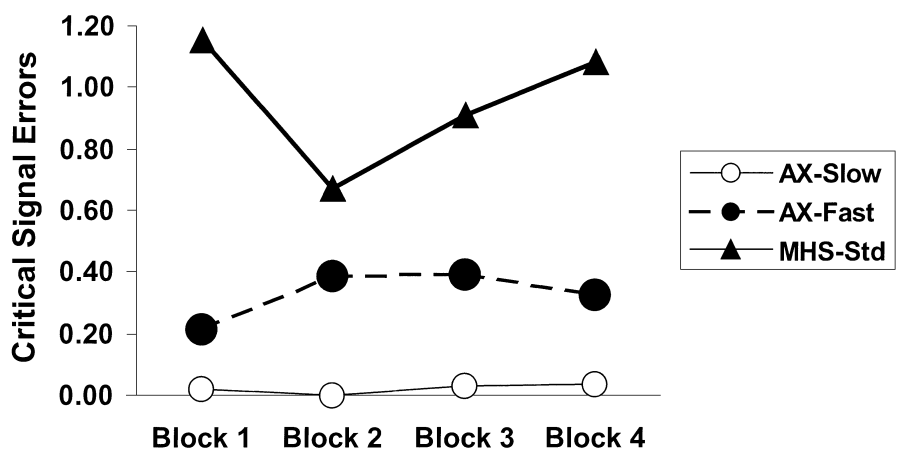

Fig. 8. Repeated-measures interaction effect of block and task type on number of critical signal errors (incorrect responses to the letter " $\mathrm{X}$ "). [AX-Slow $=$ slow event-rate traditional CPT; AX-Fast $=$ fast event-rate traditional CPT; MHS-Std = Multi-Health Systems "Standard" Task].

tion. Studies with PET and EEG are needed to determine whether the MHS-Standard, like other response-inhibition tasks such as the Stroop paradigm (see Pardo et al., 1990; Posner \& DiGirolamo, 1998) or the Wisconsin Card Sort (see Mirsky et al., 1991), taps functions of the anterior cingulate and/or the right frontal cortex.

The effects of environmental noise and participant anxiety also differed for the MHS-Standard compared to traditional CPTs. As in previous research (Ballard, 1996b), the traditional CPT with a slow event rate showed little effect of these variables, while the traditional $\mathrm{CPT}$ with a fast event rate was significantly affected by combinations of participant anxiety and environmental noise. Specifically, high-anxious participants performed best on the fast-event task in quiet noise, while low-anxious participants performed best in loud noise. Although the MHS-Standard was similar in average event rate to the slow-event rate traditional $\mathrm{CPT}$, the interaction effects of participant anxiety and environmental noise were even stronger than in the fast-event rate traditional CPT. However, the pattern of effects was reversed on the MHS-Standard, with high-anxious participants performing best in loud environmental noise, but with low-anxious participants performing best in quiet noise. Given the putative relationship of anxiety with physiological arousal, these differences in effects again suggest the operation of different brain systems.

These findings suggest several cautions in the use of the MHS-Standard. First, overall measures are not comparable to those of traditional CPTs, primarily because the errors of omission and commission differ dramatically in their relations to the critical signal for which the participant maintains a vigil. In traditional CPTs, the critical signal is also the target to which the participant responds. In contrast, the critical signal of the MHS-Standard is the non-target to which responses are prohibited. "Omissions" and "commissions" therefore represent different performance aspects on the MHS-Standard compared to traditional CPTs.

Second, the decrement function differs significantly from those in traditional CPTs. Early in the task, where a pronounced drop in speed and accuracy usually occurs for traditional CPTs, the MHS-Standard produces a decrease in speed, but an increase in accuracy. In contrast, on later trials a slight decrement in accuracy occurs, but speed again increases. It therefore appears inappropriate to characterize poor performance on this task as indicative of deficits in sustained attention. Instead, poor performance may indicate inability to adapt to task demands, a function most similar to the "executive attention" system proposed by several authors (Norman \& Shallice, 1980, 1986; Posner \& DiGirolamo, 1998; Posner \& Petersen, 1990; Posner \& Raichle, 1994). Although individuals who perform poorly on a traditional CPT may also perform poorly on a response-inhibition task, this relationship has not yet been demonstrated for the MHS-Standard. Therefore, although diagnoses of "attention deficits" should never be based on task performance alone, it should be noted that deficits identified via MHS- 
Standard performance may not be comparable to deficits identified via traditional CPTs.

The task comparisons reported in the present study are limited in that contributions of specific task parameters to performance differences cannot be identified. The goal of the present study was to compare "typical" versions of traditional CPTs with the MHS-Standard. Future studies are needed in which only the response-inhibition requirement is altered to determine the degree to which differences in task performance are due to this factor. Within-subjects comparisons also may be useful in determining relationships between performance of traditional CPTs and responseinhibition tasks, as well as the relationships between performance of the response-inhibition task and other measures of "executive attention". The present study also used a sample of normal, young adults. Generalization to patient samples may not be warranted. Finally, the relationship of task performance to underlying brain systems was surmised in the present study on the basis of previous findings. Future studies are needed in which the metabolic or neuroelectrical activity of specific brain regions is monitored during task performance.

In sum, the MHS-Standard task differs from traditional CPTs in terms of task parameters, overall performance measures, performance changes over time, and susceptibility to effects of environmental noise and participant anxiety. The most important difference may be the responseinhibition requirement. Direct comparisons with the traditional CPT therefore may be inappropriate in both research and clinical settings. However, the MHS-Standard task may prove quite useful as a measure of the component of the attention system involving executive control.

\section{REFERENCES}

Baker, C.H. (1959). Attention to visual displays during a vigilance task: II. Maintaining the level of vigilance. British Journal of Psychology, 50, 30-36.

Ballard, J.C. (1996a). Computerized assessment of sustained attention: A review of factors affecting vigilance performance. Journal of Clinical and Experimental Neuropsychology, 18, 843-863.

Ballard, J.C. (1996b). Computerized assessment of sustained attention: Interactive effects of task demand, noise and anxiety. Journal of Clinical and Experimental Neuropsychology, 18, 864-882.

Beale, I.L., Matthew, P.J., Oliver, S., \& Corballis, M.C. (1987). Performance of disabled and normal readers on the Continuous Performance Test. Journal of Abnormal Child Psychology, 15, 229-238.

Berch, D.B., \& Kanter, D.R. (1984). Individual differences. In J.S. Warm (Ed.), Sustained attention in human performance (pp. 143-178). Chichester: John Wiley \& Sons.

Broadbent, D.E., \& Gregory, M. (1965). Effects of noise and of signal rate upon vigilance analyzed by means of decision theory. Human Factors, 7, 155-162.

Campbell, J.W., D'Amato, R.C., Raggio, D.J., \& Stephens, K.D. (1991). Construct validity of the computerized Continuous Performance Test with measures of intelligence, achievement, and behavior. Journal of School Psychology, 29, 143-150.

Chee, P., Logan, G., Schachar, R.J., Lindsay, P., \& Wachsmuth, R. (1989). Effects of event rate and display time on sustained attention in hyperactive, normal, and control children. Journal of Abnormal Child Psychology, 17, 371-391.

Conners, C.K. (1995). Conners' Continuous Performance Test computer program 3.0: User's manual. Toronto, Ontario, Canada: Multi-Health Systems Inc.

Coons, H.W., Klorman, R., \& Borgstedt, A.D. (1987). Enhancing effects of methylphenidate on sustained attention and event-related potentials of adolescent patients with attention deficit disorders. Psychophysiology, 24, 572-573.

Davies, D.R., \& Hockey, G.R.J. (1966). The effects of noise and doubling the signal frequency on individual differences in visual vigilance performance. British Journal of Psychology, 57, 381-389.

Davies, D.R., Jones, D.M., \& Taylor, A. (1984). Selective- and sustained-attention tasks: Individual and group differences. In R. Parasuraman \& D.R. Davies (Eds.), Varieties of attention (pp. 395-447). Orlando, FL: Academic Press.

Deaton, J.E., \& Parasuraman, R. (1993). Sensory and cognitive vigilance: Effects of age on performance and subjective workload. Human Performance, 6, 71-97.

Earle-Boyer, E.A., Serper, M.R., Davidson, M., \& Harvey, P.D. (1991). Continuous performance tests in schizophrenic patients: Stimulus and medication effects on performance. Psychiatry Research, 37, 47-56.

Edley, R.S., \& Knopf, I.J. (1987). Sustained attention as a predictor of low academic readiness in a preschool population. Journal of Psychoeducational Assessment, 4, 340-352.

Giambra, L.M., \& Quilter, R.E. (1988). Sustained attention in adulthood: A unique, large-sample, longitudinal and multicohort analysis using the Mackworth Clock-Test. Psychology and Aging, 3, 75-83. 
Goetsch, V.L., \& Adams, H.E. (1990). A multicomponent investigation of the interaction of generalized anxiety and phobia. Journal of Psychopathology and Behavioral Assessment, 12, 329-344.

Golombok, S., Moodley, P., \& Lader, M. (1988). Cognitive impairment in long-term benzodiazepine users. Psychological Medicine, 18, 365-374.

Hancock, P.A. (1984). Environmental stressors. In: J.S. Warm (Ed.), Sustained attention in human performance (pp. 103-142). Chichester: John Wiley \& Sons.

Hockey, R. (1984). Varieties of attentional state: The effects of environment. In R. Parasuraman \& D.R. Davies (Eds.), Varieties of attention (pp. 395-447). Orlando, FL: Academic Press.

Kaufmann, P.M., Fletcher, J.M., Levin, H.S., Miner, M.E., \& Ewing-Cobbs, L. (1993). Attentional disturbance after pediatric closed head injury. Journal of Child Neurology, 8, 348-353.

Knopf, I.J., \& Mabel, R.M. (1975). Vigilance performance in second graders as a function of interstimulus intervals, socio-economic levels, and reading. Merrill-Palmer Quarterly, 21, 195-203.

Koelega, H.S., \& Brinkman, J.A. (1986). Noise and vigilance: An evaluative review. Human Factors, 28, 465-481.

Krueger, G.P. (1989). Sustained work, fatigue, sleep loss and performance: A review of the issues. Work and Stress, 3, 129-141.

Levy, F. (1980). The development of sustained attention (vigilance) and inhibition in children: Some normative data. Journal of Child Psychology and Psychiatry, 21, 72-84.

Linnoila, M., Erwin, C.W., Cleveland, W.P., Logue, P.E., \& Gentry, W.D. (1978). Effects of alcohol on psychomotor performance of men and women. Journal of Studies on Alcohol, 39, 745-758.

Loeb, M. (1986). Noise and human efficiency. Chichester: John Wiley \& Sons.

Loeb, M., \& Alluisi, E.A. (1984). Theories of vigilance. In J.S. Warm (Ed.), Sustained attention in human performance (pp. 179-205). Chichester: John Wiley \& Sons.

Mackworth, N.H. (1950). Researches on the measurement of human performance. Medical Research Council Special Report Series No. 268. London: HM Stationery Office. Reprinted in H.W. Sinaiko (Ed.), Selected papers on human factors in the design and use of control systems (pp. 174-331). New York: Dover.

McGrath, J.J. (1968). The effect of irrelevant environmental stimulation on vigilance performance (Technical Report 6, November, 1960). In Studies of human vigilance: An omnibus of technical reports (pp. 235-293). Goleta, CA: Human Factors Research, Incorporated.

McGrath, J.J., \& Hatcher, J.F. (1968). Irrelevant stimulation and vigilance under fast and slow stimulus rates (Technical Report 7, February, 1961). In Studies of human vigilance: An omnibus of technical reports (pp. 295-310). Goleta, CA: Human Factors Research, Incorporated.

McGrath, J.J., Harabedian, A., \& Buckner, D.N. (1968). Review and critique of the literature on vigilance performance (Technical Report 206-1, December, 1959). In Studies of human vigilance: An omnibus of technical reports (pp. 1-108). Goleta, CA: Human Factors Research, Incorporated.

Mesulam, M.M. (1981). A cortical network for directed attention and unilateral neglect. Annals of Neurology, 10, 309-325.

Mirsky, A.F., Anthony, B.J., Duncan, C.C., Ahearn, M.B., \& Kellam, S.G. (1991). Analysis of the elements of attention: A neuropsychological approach. Neuropsychology Review, 2, 109-145.

Mirsky, A.F., Lochhead, S.J., Jones, B.P., Kugelmass, S., Walsh, D., \& Kendler, K.S. (1992). On familial factors in the attentional deficit in schizophrenia: A review and report of two new subject samples. Journal of Psychiatric Research, 26, 383-403.

Norman, D.A., \& Shallice, T. (1980). Attention to action: Willed and automatic control of behavior (Technical Report No. 99). La Jolla, CA: Center for Human Information Processing.

Norman, D.A., \& Shallice, T. (1986). Attention to action: Willed and automatic control of behavior. In R.J. Davidson, G.E. Schwartz, \& D. Shapiro (Eds.), Consciousness and self-regulation (pp. 1-18). New York: Plenum Press.

Parasuraman, R. (1979). Memory load and event rate control sensitivity decrements in sustained attention. Science, 205, 924-927.

Parasuraman, R. (1984). The psychobiology of sustained attention. In J.S. Warm (Ed.), Sustained attention in human performance (pp. 61-101). Chichester: John Wiley \& Sons.

Parasuraman, R. (1998). The attentive brain: Issues and prospects. In R. Parasuraman (Ed.), The attentive brain (pp. 3-15). Cambridge, MA: The MIT Press.

Parasuraman, R., \& Giambra, L. (1991). Skill development in vigilance: Effects of event rate and age. Psychology and Aging, 6, 155-169.

Parasuraman, R., \& Haxby, J.V. (1993). Attention and brain function in Alzheimer's disease: A review. Neuropsychology, 7, 242-272.

Parasuraman, R., \& Mouloua, M. (1987). Interaction of signal discriminability and task type in vigilance decrement. Perception and Psychophysics, 41, 1722.

Parasuraman, R., Mutter, S.A., \& Molloy, R. (1991). Sustained attention following mild closed-head injury. Journal of Clinical and Experimental Neuropsychology, 13, 789-811.

Parasuraman, R., Warm, J.S., \& See, J.E. (1998). Brain systems of vigilance. In R. Parasuraman (Ed.), The 
attentive brain (pp. 221-256). Cambridge, MA: The MIT Press.

Pardo, J.V., Pardo, P.J., Janer, K.W., \& Raichle, M.E. (1990). The anterior cingulate cortex mediates processing selection in the Stroop attentional conflict paradigm. Proceedings of the National Academy of Science USA, 87, 256-259.

Posner, M.I., \& DiGirolamo, G.J. (1998). Executive attention: Conflict, target detection, and cognitive control. In R. Parasuraman (Ed.), The attentive brain (pp. 401-423). Cambridge, MA: The MIT Press.

Posner, M.I., \& Petersen, S.E. (1990). The attention system of the human brain. Annual Review of Neuroscience, 13, 25-42.

Posner, M.I., \& Raichle, M. (1994). Images of mind. New York: McGraw-Hill.

Rapport, M.D., Carlson, G.A., Kelly, K.L., \& Pataki, C. (1993). Methylphenidate and desipramine in hospitalized children. I. Separate and combined effects on cognitive function. Journal of the American Academy of Child and Adolescent Psychiatry, 32, 333-342.

Rohrbaugh, J.W., Stapleton, J.M., Parasuraman, R., Frowein, H.W., Adinoff, B., Varner, J.L., Zubovic, E.A., Lane, E.A., Eckardt, M.J., \& Linnoila, M. (1988). Alcohol intoxication reduces visual sustained attention. Psychopharmacology, 96, 442-446.

Rosvold, H., Mirsky, A., Sarason, I., Bransome, E., \& Beck, L. (1956). A continuous performance test of brain damage. Journal of Consulting Psychology, 20, 343-350.

Schiff, A.R., \& Knopf, I.J. (1985). The effects of task demands on attention allocation in children of different ages. Child Development, 56, 621-630.
Seidel, W.T., \& Joschko, M. (1991). Assessment of attention in children. The Clinical Neuropsychologist, 5, 53-66.

Smith, A. (1989). A review of the effects of noise on human performance. Scandinavian Journal of Psychology, 30, 185-206.

Smith, A.P., Kendrick, A.M., \& Maben, A.L. (1992). Effects of breakfast and caffeine on performance and mood in the late morning and after lunch. Neuropsychobiology, 26, 198-204.

Spielberger, C.D., Gorsuch, R.L., Lushene, R.E., Vagg, P.R., \& Jacobs, G.A. (1983). Manual for the StateTrait Anxiety Inventory (Form Y) (Self-Evaluation Questionnaire). Palo Alto: Consulting Psychologists Press.

Spielberger, C.D., Vagg, P.R., Barker, L.R., Donham, G.W., \& Westberry, L.G. (1980). The factor structure of the State-Trait Anxiety Inventory. In I.G. Sarason \& C.D. Spielberger (Eds.), Stress and anxiety, (Vol. 7, pp. 95-109). Washington DC: Hemisphere Publishing Corp.

Tarver, S.G., \& Hallahan, D.P. (1974). Attention deficits in children with learning disabilities: A review. Journal of Learning Disabilities, 7, 560-569.

Warm, J.S., \& Jerison, H.J. (1984). The psychophysics of vigilance. In J.S. Warm (Ed.), Sustained attention in human performance (pp. 15-59). Chichester: John Wiley \& Sons.

Warner, H.D., \& Heimstra, N.W. (1972). Effects of noise intensity on visual target-detection performance. Human Factors, 14, 181-185. 